\section{A música no ensino de geografia: abordagem lúdica do semiárido nordestino - uma proposta didático-pedagógica}

Suellen Silva Pereira*

\begin{abstract}
Resumo: O presente artigo consiste em um ensaio teórico que tem por objetivo analisar a utilização da música como ferramenta didático-pedagógica nas aulas de Geografia, neste caso, mais especificadamente, será realizada uma abordagem relacionando conteúdos referentes à Geografia presentes nas letras das músicas de Luiz Gonzaga, haja vista toda a regionalidade encontrada nestas canções, destacando elementos característicos do semiárido, como forma de aproximar os alunos do seu cotidiano; além de refletir sobre a importância da educação ambiental para a preservação do meio ambiente, como forma de desmistificar os estigmas que envolvem a região em análise. Para tanto, recorreu-se a pesquisa bibliográfica e musiográfica. Com isso, buscase despertar no professor sua importância como agente formador de opinião e não apenas como um mero reprodutor de conteúdos.
\end{abstract}

\section{Music in the teaching of geography: playful approach of semi-arid northeastern - a proposal didactic and pedagogic}

\begin{abstract}
This article consists of a paper that aims to examine the use of music as a didactic and pedagogic tool in geography lessons, in this case, more specifically, an approach will be made relating issues related to geography present in the lyrics of songs by Luiz Gonzaga , considering all the regionality found in these songs, highlighting elements characteristic of semi-arid, as a way of bringing students from your everyday life, in addition to reflecting on the importance of environmental education for the preservation of the environment as a way to demystify the stigma surrounding the region under analysis. For this, we used a literature search and musiográfica. Thus, we seek to awaken in its importance as a teacher trainer agent of opinion and not as a mere player content.
\end{abstract}

* Licenciada em Geografia - UEPB, Mestre em Desenvolvimento e Meio Ambiente - PRODEMA UFPB/UEPB, Bolsista CNPq, Doutoranda em Recursos Naturais - UFCG, Doutoranda em Geografia - UFPE

\section{Palavras-chave: \\ Ensino de Geografia; Semiárido; Música; Luiz Gonzaga.}

\section{Key-words:}




\section{Introdução}

A utilização de mídias em sala de aula vem se configurando em uma alternativa didáticopedagógica. Dentre as várias possibilidades midiáticas, destaca-se a utilização da música em sala de aula, haja vista a variedade de gêneros musicais, a facilidade de acesso às letras, bem como 0 fato de que dificilmente se encontrará alguém que não goste de música. Favorecendo, com isso, uma aproximação maior do aluno com os conteúdos trabalhados, principalmente se a música escolhida apresentar elementos comuns ao cotidiano destes.

Desse modo, o presente artigo se configura em uma proposta didático-pedagógica para se trabalhar conteúdos geográficos levando em consideração os elementos que constituem a paisagem local, utilizando para tanto a música como recurso metodológico. Neste caso, recorreramse as músicas de Luiz Gonzaga para se trabalhar conteúdos referentes à Geografia, utilizando os elementos regionais presentes nas referidas canções.

Diante do exposto, o presente artigo tem por objetivo analisar a utilização de música como ferramenta didático-pedagógica nas aulas de Geografia, neste caso, mais especificadamente, nas letras das músicas de Luiz Gonzaga, haja vista toda a regionalidade encontrada nestas canções, destacando elementos característicos do semiárido, como forma de aproximar os alunos do seu cotidiano, uma vez que praticamente todos os Estados Nordestinos se encontram dentro das delimitações do semiárido, tornando-se necessário o conhecimento e valorização dos elementos que compõem tal região; ainda será realizada uma reflexão da importância da educação ambiental como instrumento de conscientização para a preservação do meio ambiente, tendo em vista os estigmas que envolvem a região em análise.

Assim sendo, a presente pesquisa se caracteriza por ser um ensaio teórico. Como estratégia metodológica, foi feito uma pesquisa bibliográfica em algumas publicações de maior relevância, no que concerne ao tema e, a partir desta, foi desenvolvida uma análise crítica, de modo a alcançar os objetivos propostos. Posteriormente, foi realizada uma pesquisa musiográfica nas letras de Luiz Gonzaga, como forma de selecionar músicas com elementos característicos do semiárido nordestino, de modo que estas possam vir a ser utilizadas nas aulas de Geografia de maneira mais dinâmica e interessante para os alunos.

Com isso, busca-se despertar no professor sua importância como agente formador de opinião e não apenas como um mero reprodutor de conteúdos. Para tanto, esse profissional deve procurar adequar-se às novas mudanças no processo de ensino-aprendizagem e às inovações tecnológicas, que colocam a disposição recursos que podem ser utilizados em sala, de modo a tornar suas aulas mais interativas e propiciar uma maior participação do alunado, tornado, com isso, o conteúdo significativo ao relacioná-lo com a realidade vivida dos educandos.

\section{A prática pedagógica em Geografia: necessidade de novas abordagens teórico- metodológicas}

Considerando a responsabilidade do professor de Geografia, diante da formação de alunos críticos/reflexivos, é preciso enfatizar que tanto as possibilidades tecnológicas mais recentes na infraestrutura escolar, quanto àquelas consideradas mais tradicionais, como o uso do quadro de

Geografia Ensino \& Pesquisa, v. 16, n.3 p. 137-148, set./dez. 2012

A música no ensino de geografia: abordagem lúdica do semiárido nordestino - uma proposta didático-pedagógica giz, do livro didático, de cartazes, jornais ou revistas, devem ser cercadas de cuidados didáticopedagógicos para que alcancem resultados significativos no ensino. Vesentini $(2001$, p. 30) realça, com muita propriedade, esta situação ao discorrer que: 
instrumentos da geografia escolar -, como também psicogenética, existencial, social e econômica. Se os educandos são fascinados pelos computadores, pela imagem no lugar da escrita, por jogos, então é interessante incorporar tudo isso na estratégia de ensino. Afinal o professor também é um cidadão que vive no mesmo mundo pleno de mudanças do educando e ele também deve estar a par e participar das inovações tecnológicas, das alterações culturais.

De acordo com Kaercher (2002), é necessário introduzir uma Geografia Crítica em sala de aula, que instigue no aluno a curiosidade de descobrir novos fatos, de aprofundar seus conhecimentos. Mas, na concepção do autor, o que se vê é apenas uma mudança de rótulo ou slogan da Geografia que está em sala de aula, com isso, os professores continuam a produzir verdades cristalizadas e, o que é pior, mantendo a Geografia como algo chato e distante do cotidiano dos alunos.

Mesmo sendo a Geografia essencial para a compreensão das relações espaciais, entre o homem e o espaço geográfico, como também para a formação de uma base crítica, o que possibilita a análise de fatores sociais, políticos e econômicos, esta ciência não é encarada dessa forma, principalmente em se tratando da Geografia Física (haja vista toda a carga descritiva agregada aos seus conteúdos. Ex: descrição do relevo, características climáticas, estruturas geológicas e geomorfológicas, dentre outros), o que a fez ficar conhecida como uma disciplina "chata" de ser estudada e desenvolvida, ao ponto de ser taxada pelos alunos como uma disciplina de "pura decoreba".

Com a modernização nos meios de comunicação e a consequente expansão da tecnologia, faz-se necessário uma modificação no método de ensino-aprendizagem, para que este possa acompanhar 0 processo evolutivo, adequando-se as novas exigências da sociedade. Nesse contexto, é de fundamental importância à renovação do ensino de geografia, baseada na inovação de materiais didático-pedagógicos que possibilitem aos alunos um novo olhar para tal disciplina, despertando o interesse destes pelas aulas. De acordo com Pinheiro et. al. (2004, p. 104):

Para romper esse estigma, alguns professores buscam várias maneiras de renovar e inovar o ensino. Nas transformações por que passa a escola, com vista à reformulação dos métodos educacionais, os materiais didáticos são de fundamental importância no trabalho do professor. Eles se constituem em instrumentos que possibilitam planejar boas situações didáticas, buscando promover a ampliação dos conhecimentos dos alunos, permitindo-lhes desenvolver conceitos, problematizar questões e articular conteúdos. Para isso, 0 professor deverá criar situações concretas de aprendizagem.

A constatação evidenciada no fragmento de texto acima exposto pode ser corroborada pelos Parâmetros Curriculares Nacionais - PCN's, quando estes, ao discorrerem sobre as práticas de ensino da Geografia, afirmam que:

O ensino de Geografia, de forma geral, é realizado por meio de aulas expositivas ou da leitura dos textos do livro didático. Entretanto, é possivel trabalhar com esse campo do conhecimento de forma mais dinâmica e instigante para os alunos, mediante situações que problematizem os diferentes espaços geográficos materializados em paisagens, lugares e territórios; que disparem relações entre o presente e o passado, o específico e o geral, as ações individuais e as coletivas; e promovam o domínio de procedimentos que permitam aos alunos "ler" a paisagem local e outras paisagens presentes em outros tempos e espaços (BRASIL, 2001, p. 153).

É importante ressaltar que os equipamentos que permitem essas práticas não podem ser priorizados pela metodologia de aprendizagem, apenas pelo seu simples domínio e uso. São as formas de usar suas possibilidades de comunicação e de informação que se constituem

Geografia Ensino \& Pesquisa, v. 16, n.3 p. $137-148$, set./dez. 2012

Pereira, S. S.

ISSN 2236-4994 
alternativas didáticas. Assim, projetar um filme, acessar a internet, capturar um texto, assistir a um programa televisivo, escrever um texto no computador são ações que se tornam educativas pela intencionalidade pedagógica do ensinar e do aprender, não porque são práticas do nosso tempo (MELO et. al., s/d).

\section{A música como instrumento de aproximação entre o aluno e a geografia}

A música (som e letra) pode ser utilizada na problematização do cotidiano e na formação do cidadão de forma mais lúdica e interativa, tendo em vista a amplitude de abordagens que podem ser identificadas nos diversos gêneros musicais. Tal constatação também pode ser evidenciada nas palavras de Dohme (2009, p. 57/58), quando a autora argumenta que:

[...] o uso da música como um meio de expressão, como um elemento que propicia momentos lúdicos e como este aspecto proporciona o desenvolvimento individual e o convívio em grupo. [...] Não resta dúvida que este contacto é uma forma de despertar, e poderá ser um instrumento para identificar o gosto pela música incentivando o seu estudo e aprimoramento, mas também é verdade que este uso da arte musical leva a experiências outras, como a sociabilização, desinibição, criatividade, descoberta e formação da autoestima [...].

Diante do exposto, cabe ao professor desenvolver reflexões sobre o desenvolvimento da sua prática pedagógica, assim como ressalta Paulo Freire (2009, p. 22), "a reflexão crítica sobre a prática se torna uma exigência da relação Teoria/Prática sem a qual a teoria pode ir virando blábláblá e a prática, ativismo", como forma de buscar a renovação do processo de ensino-aprendizagem, adequando sua prática as especificidades de cada turma.

De acordo com Oliveira et. al. (2005), aliar essa facilidade de assimilação encontrada nos mais diversos gêneros musicais às propostas metodológicas e curriculares da Geografia pode gerar bons resultados. Dificilmente se encontrará algo mais atrativo, entre crianças e jovens, do que 0 compartilhar suas preferências, sua reprovação ou aprovação às obras musicais, com seus colegas e professores. Com a música, é possível ainda despertar e desenvolver nos alunos sensibilidades mais aguçadas na observação de questões próprias à disciplina alvo (FERREIRA, 2010, p. 13).

$A$ variedade de conteúdos e gêneros musicais que se encontram a disposição do professor pode ser um fator facilitador de sua utilização em sala de aula, como demonstrado por Costa (2002 apud PINHEIRO et. al., 2004, p. 104) ao abordar que:

Uma das vantagens de se utilizar a música na Geografia se afirma na pluralidade de assuntos abordados por esta ciência. Violência, guerras, conflitos raciais, fome, falta de infraestrutura nas cidades, belezas naturais, como também degradação ao meio ambiente, fazem parte dos temas abordados por muitos compositores [...].

O referido autor complementa as suas colocações sobre a utilização da música nas aulas de

Geografia Ensino \& Pesquisa, v. 16, n. 3 p. 137-148, set./dez. 2012

A música no ensino de geografia: abordagem lúdica do semiárido nordestino - uma proposta didático-pedagógica
A educação da Geografia através da música proporciona a vivência da linguagem musical como um dos meios de representação do saber construído pela interação intelectual e afetiva do homem com o meio ambiente, pois a interação naturezasociedade faz parte do cotidiano de todos os seres humanos do planeta (COSTA apud PINHEIRO, op. cit., p. 105). 
Com isso, cabe ao professor fazer uma escolha criteriosa das músicas a serem trabalhadas com seus alunos em sala de aula, analisando a sua adequação com a temática em estudo, e o que a esta tem a oferecer para um maior enriquecimento das aulas a serem ministradas; extraindo do alunado sua posição crítica diante do estudo; buscando sempre uma correlação com a temática proposta e o cotidiano dos alunos, como forma de fornecer significância aos conteúdos apreendidos, rompendo com o rótulo de "uma disciplina sem serventia" que é atribuído à geografia escolar.

\section{Semiárido, educação ambiental e música nas aulas de geografia}

Muito se questiona sobre a organização dos conteúdos apresentados nos livros didáticos, principalmente no que se refere à descontextualização destes para com o espaço vivido dos alunos. Tais questionamentos acentuam-se quando analisados os conteúdos referidos a Geografia do Nordeste, haja vista que estes se apresentam carregados de estigmas e preconceitos, sempre destacando e associando as características climáticas como o principal fator para os problemas socioeconômicos e ambientais da região.

Diante desse contexto, cabe ao professor recorrer a outros instrumentos didáticos, como forma de complementar as discussões em sala de aula, de modo a favorecer a construção reflexiva e crítica do aluno, tomando como base o cotidiano deste. No intuito de contribuir para a desmistificação da região semiárida do nordeste brasileiro, a utilização de músicas que retratem a realidade local pode vir a ser uma boa alternativa, visto toda a riqueza e diversidade musiográfica existente, bem como a aceitabilidade por parte dos discentes em se trabalhar com este tipo de recurso.

A utilização de músicas pode ainda auxiliar na prática educativa, no que se refere a ações ambientalmente responsáveis, através do desenvolvimento da percepção destes alunos para as potencialidades da região e, por conseguinte, valorização do patrimônio material e imaterial. Contribuído, com isso, para um desenvolvimento da região pautado na sustentabilidade.

\section{O semiárido nordestino: algumas considerações}

Segundo Andrade (2005), o Nordeste é uma das regiões geográficas mais discutidas do país, apesar de ser ainda a menos conhecida. Frequentemente, a área é associada ao fenômeno das secas - característico de parte significativa da região - e das consequências sobre a população local, entretanto nem todo o Nordeste é castigado pela estiagem e, por este motivo e para melhor administrar tal fato, nas áreas mais afetadas desse território foi delimitada a região que compreende, de acordo com os critérios estabelecidos, as maiores adversidades condicionadas pela semiaridez climática. Essa área é denominada de Polígono das Secas ou, mais comumente, de semiárido (apud MELO; PEREIRA \& PEREIRA, 2008, p. 1572).

A última atualização dos municípios pertencentes ao semiárido, feita pela Superintendência de Desenvolvimento do Nordeste - SUDENE foi em 1995, através da Portaria 1.181 do referido órgão. Com a extinção da Autarquia mencionada, passou-se para o Ministério da Integração Nacional a responsabilidade de posicionar-se acerca dos pleitos de inclusão dos municípios interessados em dispor de tratamento diferenciado das políticas de crédito e benefícios fiscais conferidos a essa parcela do território brasileiro (MELO; PEREIRA \& PEREIRA, op. cit.).

O Ministério da Integração instituiu, em 2005, uma nova delimitação para a área em foco (Figura 1), atualizando os critérios de classificação a partir de três variáveis climáticas ao invés de uma, a saber: I. precipitação pluviométrica média anual inferior a 800 milímetros; II. Índice de aridez de até 0,5 calculado pelo balanço hídrico que relaciona as precipitações e a evapotranspiração potencial, no período entre 1961 e 1990; e III. Risco de seca maior que $60 \%$, tomando-se por base o período entre 1970 e 1990 (BRASIL, 2005).

Geografia Ensino \& Pesquisa, v. 16, n.3 p. 137-148, set./dez. 2012

Pereira, S.S.

ISSN 2236-4994 141 
Figura 1- Delimitação do semiárido brasileiro.

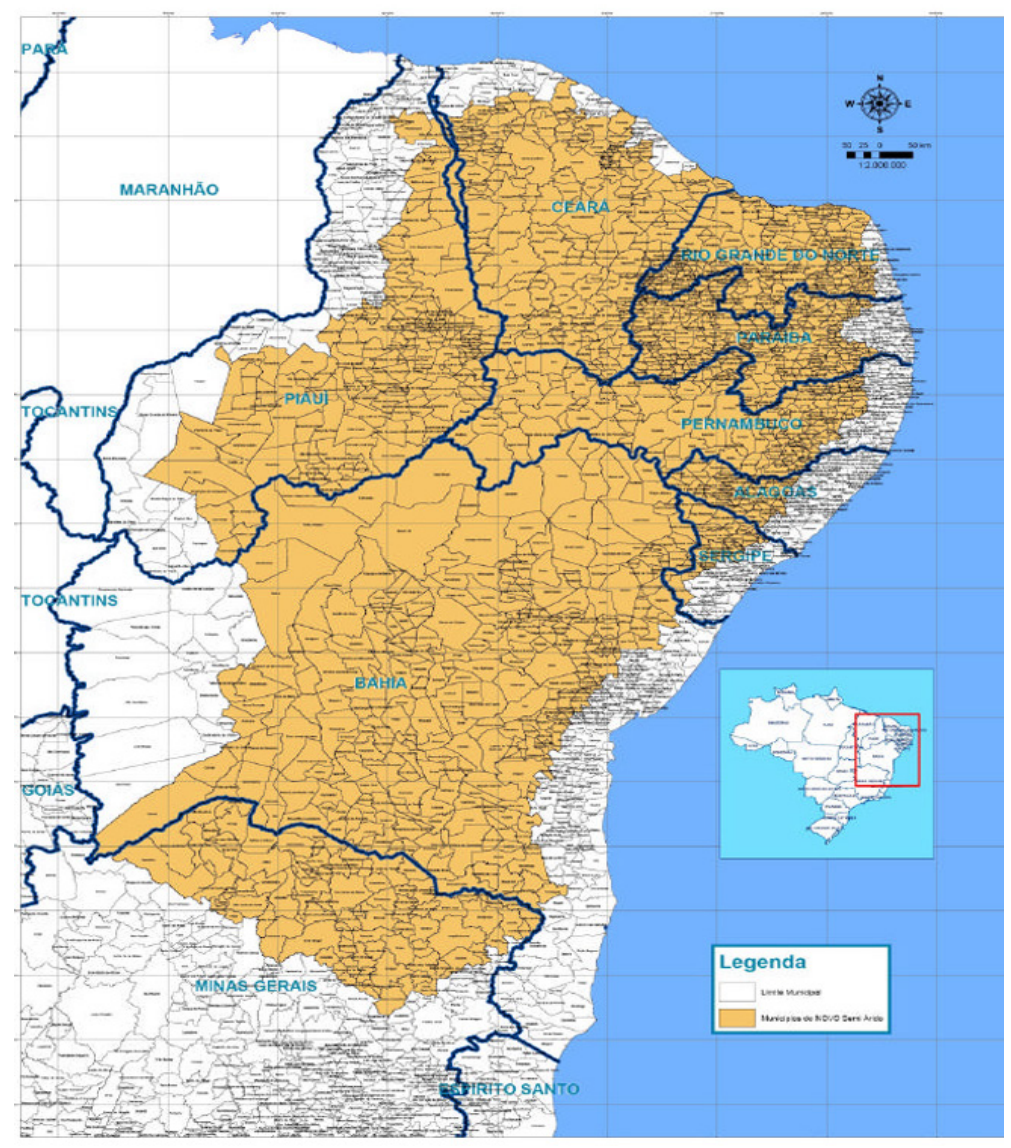

Fonte: Ministério da Integração Nacional (BRASIL, 2005).

De acordo com Melo, Pereira \& Pereira (op. cit.), com essa atualização, a área classificada oficialmente como Polígono das Secas aumentou de $892.309,4 \mathrm{~km}^{2}$ para $969.589,4 \mathrm{~km}^{2}$, sendo composta por 1.133 municípios, com uma população de 20.858.264 habitantes.

Segundo apreciação informal feita por Jean Dresch e mencionada por Ab'Sáber (2003), a região em pauta é uma das áreas semi-áridas mais povoadas entre todas as terras secas existentes nos trópicos, entretanto este último autor complementa a informação acrescentando que, possivelmente, se trata da região que possui a estrutura agrária mais rígida da face da Terra (apud MELO; PEREIRA \& PEREIRA, 2008, p. 1573).

\section{Educação ambiental para preservação do Semiárido}

A educação ambiental é um processo participativo que deve buscar valores que conduzam a uma convivência harmônica com todas as espécies que compartilham 0 ambiente natural com 0 homem. Assim, a educação ambiental deve levar o ser humano a repensar e refletir, criticamente, o princípio de que tudo que há na natureza não pode ser utilizado de forma irracional, com a destruição

Geografia Ensino \& Pesquisa, v. 16, n. 3 p. 137-148, set./dez. 2012

A música no ensino de geografia: abordagem lúdica do semiárido nordestino - uma proposta didático-pedagógica dos recursos naturais e de vários espécimes animais e vegetais (FRANÇA \& FIGUEIREDO, 2010).

As premissas estabelecidas por Paulo Freire sobre a educação ambiental pode ser muito bem empregadas para as atividades político-pedagógicas que venham a ser desenvolvida nas regiões semiáridas, haja vista a necessidade de levar em consideração, principalmente, o conhecimento empírico e a cultura local da comunidade alvo. Os pontos destacados pelo supracitado autor são os seguintes: 
-Valorização do conhecimento do aprendiz, de sua historia de vida e de sua cultura;

-Elaboração de um plano de trabalho político-pedagógico, de caráter coletivo, que respeite a participação de todos e de cada um no processo permanente e coletivo de construção do conheci mento;

-Prática efetiva e permanente de diálogo com a comunidade;

- Orientação à investigação e à pesquisa dos problemas ambientais locais;

- Desenvolvimento de habilidades e hábitos de uso adequado e científico das fontes históricas;

-Participação efetiva de todos na definição dos temas e projetos de trabalho;

-Estímulo permanente à discussão, à construção de hipóteses, ao enfrenta mento das dúvidas e ao exercício de estimativas;

-Desenvolvimento de habilidades de análise, comparação, justificação, argumentação, síntese e intervenção (FREIRE, 1996 apud FRANÇA \& FIGUEIREDO, op. cit., p. 14/15).

Na concepção de Braga (2004), a convivência com o semiárido é central nas experiências e nas práticas sociais desenvolvidas neste território. É um contexto nos quais fatores climáticos, sócio-históricos, políticos, econômicos e ambientais precisam ser considerados para que se entenda o papel e o sentido da educação no trabalho político-educativo desenvolvido na Região. Fazendo extremamente necessário a compreensão de como esses fatores são determinantes para as populações que estão construindo suas condições de vida e relações com o meio ambiente, baseadas não na idéia do combate à seca, mas na lógica da convivência.

Segundo Pimentel (2000 apud BRAGA, op. cit.), a lógica do combate à seca sempre é percebida quando nos aproximamos das idéias e ações governamentais, uma vez que elas são elaboradas dentro da lógica que invade e mutila o território para garantir sua ocupação. Da colonização aos dias atuais, o que mudou foram as estratégias, mas a lógica continua sendo a mesma: das plantações de mandioca para as plantações de uva, manga, aspargos etc. A prioridade sempre foi à exploração da riqueza do semiárido, sobretudo dos recursos hídricos.

Essa noção institucionalizou uma visão equivocada, ideologicamente elaborada pelas elites oligárquicas e pelo Estado, de que o problema do semiárido é a seca, e este território passa a ser visto como uma "Odisséia de Desvalidos". Por isso é que é importante compreender em que se fundamenta a lógica do combate à seca, pois é ela que afirma a presença do poder do Estado na elaboração de suas políticas para o semiárido (IDEM).

Cavalcanti (2003, p. 46) faz um apanhado dessas mudanças ao criticar as visões paternalistas e emergenciais do combate à seca e diz que "a perspectiva da convivência não significa passividade, mas, pelo contrário, requer uma maneira diferente de estruturar o conhecimento sobre o semiárido". Afinal, conforme Pinto (2002, p. 401), "a seca não é um problema, a seca é um equívoco. A solução do equívoco da seca não será a supressão da seca, mas seu aproveitamento ecológico, econômico e estratégico".

Neste contexto, a importância da abordagem da educação ambiental incide diretamente na compreensão das especificidades inerentes da citada região, como forma, primeira, de reconhecer suas limitações e potencialidades, com o intuído, posteriormente, de um melhor direcionamento das ações empreendidas no semiárido.

\section{O semiárido nordestino nas músicas de Luiz Gonzaga}

O semiárido brasileiro foi retratado com bastante fidedignidade nas canções de Luiz Gonzaga, o qual deixou um rico acervo musical, podendo este ser explorado em sala de aula de modo a trabalhar os conteúdos geográficos, relacionando-os com os elementos característicos desta

Geografia Ensino \& Pesquisa, v. 16, n.3 p. 137-148, set./dez. 2012

Pereira, S. S.

ISSN 2236-4994 
região, uma vez que $76,2 \%$ dos municípios paraibanos se encontram dentro da nova delimitação do semiárido, fazendo-se necessário que as escolas inseridas nessas localidades passe a trabalhar com uma educação contextualizada com a realidade dos educandos, podendo uma dessas iniciativas perpassarem por um reconhecimento e, consequente, valorização dos elementos que compõem tais localidades, quer sejam o clima, a vegetação, o relevo, a hidrografia, a cultura, dentre outros.

Assim sendo, foi realizada uma pesquisa musiográfica das canções de Luiz Gonzaga, sendo selecionadas, para esta análise, três letras que retratam a realidade do semiárido nordestino, com todas as suas especificidades.

Desse modo, serão apresentadas propostas de trabalho com as referidas letras, de modo a subsidiar os professores com os conteúdos referentes à Geografia do Nordeste, relacionando-os com os elementos que constituem o meio em que a escola está inserida, levando em consideração o conhecimento prévio do aluno, como ressalta Cavalcanti ao discorrer sobre a perspectiva socioconstrutivista proposta por Vygotsky. De acordo com a referida autora:

A perspectiva socioconstrutivista (...) concebe o ensino como uma intervenção
intencional nos processos intelectuais, sociais e afetivos do aluno, buscando
sua relação consciente e ativa com os objetos de conhecimento (...). Esse
entendimento implica, resumidamente, afirmar que o objetivo maior do ensino é
a construção do conhecimento pelo aluno, de modo que todas as ações devem
estar voltadas para sua eficácia do ponto de vista dos resultados no conhecimento
e desenvolvimento do aluno. Tais ações devem pôr o aluno, sujeito do processo,
em atividade diante do meio externo, o qual deve ser 'inserido' no processo como
objeto de conhecimento, ou seja, o aluno deve ter com esse meio (que são os
conteúdos escolares) uma relação ativa, uma espécie de desafio que o leve a um
desejo de conhecê-lo (CAVALCANTI, 2002, p. 31/32).

Tomando por base as colocações de Pinheiro et. al. (2004), ressalta-se que ao se trabalhar com música em sala de aula, faz-se necessário, primeiramente, uma interpretação da letra, de modo a identificar os elementos que estão sendo representados; co-relacionar a música com os conteúdos que serão trabalhados; elencar os termos desconhecidos pelos alunos contextualizandoos para a compreensão da letra e, por conseguinte, o aprendizado.

Ressalta-se ainda a possibilidade de desenvolvimento de trabalhos interdisciplinares, envolvendo disciplinas que venham a contribuir e enriquecer o estudo, como forma de complementar as informações que estão sendo repassadas, não se restringindo apenas ao conhecimento geográfico. Abaixo segue as letras das músicas selecionadas, juntamente com os objetivos propostos.

Geografia Ensino \& Pesquisa, v. 16, n. 3 p. $137-148$, set./dez. 2012

A música no ensino de geografia: abordagem lúdica do semiárido nordestino - uma proposta didático-pedagógica

\section{I - Baião da Garoa (Luiz Gonzaga e Hervé Cordovil)}

Na terra seca/ Quando a safra não é boa/ Sabiá não entoa/ Não dá milho e feijão/ Na Paraíba, Ceará nas Alagoas/ Retirantes que passam/Vão cantando seu rojão/ Tra, lá, lá, lá, lá, lá, lá - (Bis)/ Meu São Pedro me ajude/ Mande chuva, chuva boa/ Chuvisquinho, chuvisqueiro/ Nem que seja uma garoa/ Uma vez choveu na terra seca/ Sabiá então cantou/ Houve lá tanta da fartura/ Que o retirante voltou/ Tava lá eu na pisada (2x)/Tum, tum, Tum/ Oi! Graças a Deus/ Choveu, garoou.

O objetivo principal desta atividade é estudar as condições climáticas da Região Nordeste e sua interferência na agricultura, dessa forma, pretende-se:

1. Identificar os elementos climáticos presente na letra da música;

2. Destacar, utilizando o mapa climático e de vegetação da região Nordeste, qual a interferência do clima na configuração da paisagem local; 
3. Elencar elementos que sejam comuns ao cotidiano dos alunos, de modo a aproximar 0 conteúdo do seu espaço vivido, com vista à construção de uma geografia mais humanista;

4. Relacionar a interferência climática para o desenvolvimento da atividade agrícola;

5. Pesquisar sobre as principais culturas desenvolvidas na região onde moram e a importância desta atividade para a vida dos agricultores; bem como de suas famílias;

6. Discutir sobre a importância da água para a atividade agrícola; bem como investigar alternativas de convivência com a escassez típica da região semiárida, compreendendo a seca como um fenômeno natural.

\section{II - Pobreza por Pobreza (Luiz Gonzaga)}

Meu sertão vai se acabando/ Nessa vida que o devora/ Pelas trilhas só se vê gente boa indo embora/ Mas a estrada não terá o meu pé pra castigar/

Meu agreste vai secando/ E com ele vou secar/ Pra que me largar no mundo se nem sei se vou chegar/ A virar em cruz de estrada/ Prefiro ser cruz por cál Ao menos o chão que é meu/ Meu corpo vai adubar/ Ao menos o chão que é meu Meu corpo vai adubar/Se doente sem remédio, remediado está/ Nascido e criado aquil Sei o espinho aonde dál Pobreza por pobrezal Sou pobre em qualquer lugar/ A fome é a mesma fome que vem me desesperar/ $E$ a mão é sempre a mesma que vive a me explorar (2x)/ Se doente sem remédio, remediado estál Nascido e criado aqui/ Sei o espinho onde dá/ Pobreza por pobreza/ Sou pobre em qualquer lugar.

O objetivo desta atividade é trabalhar o fenômeno da migração nordestina, para tanto, 0 aluno será orientado a:

1. Identificar possíveis elementos que fazem com que a população sertaneja busque outras cidades para obtenção de uma melhor qualidade de vida e de trabalho;

2. Discutir, de forma crítica e reflexiva, quais os reais fatores que contribuem para a pobreza da população sertaneja, colocando no cerne das discussões os elementos climáticos, bem como os fatores políticos e econômicos;

3. Pesquisar na localidade onde o aluno reside, famílias que tenham parentes que migraram para outras regiões, registrando os motivos pelos quais estes deixaram a cidade natal e qual o destino que tomaram. Posteriormente, em um mapa, poderá ser criada uma rota com os principais destinos da população que migrou. Por fim, ainda pode ser feito uma pesquisa com os migrantes retornados, investigando os motivos que os trouxeram de volta para a sua cidade natal;

4. Fazer um levantamento, utilizando para tanto os meios de comunicação (telejornais, jornais escritos, internet, dentre outros), sobre as condições de vida dos migrantes nordestinos nos seus principais destinos de moradia, destacando, principalmente a Região Sudeste do Brasil. Em seguida, sugere-se um estudo comparativo relacionando os dados da pesquisa com observações realizadas in loco, como forma de discutir a organização do espaço geográfico investigado através dos elementos que compõe este espaço;

5. Refletir com a turma o que o compositor quis transmitir através destas estrofes: "Nascido e criado aqui/ Sei o espinho aonde dál Pobreza por pobreza/ Sou pobre em qualquer lugar";

6. Discutir como as condições climáticas sempre foram utilizadas para justificar as condições de pobreza do nordeste, perguntando aos alunos o que eles pensam a respeito. Podendo ser solicitada uma produção textual, como forma de verificar o entendimento do aluno nas discussões desenvolvidas.

Geografia Ensino \& Pesquisa, v. 16, n.3 p. $137-148$, set./dez. 2012 
encontrar/ Cadê a flor que estava aqui?/ Poluição comeu/ E o peixe que é do mar?/ Poluição comeu/ E o verde onde que está?/ Poluição comeu/ Nem o Chico Mendes sobreviveu.

A presente atividade objetiva, principalmente, refletir sobre as questões ambientais que assola o país, trazendo tal discussão para a realidade semiárida, haja vista que o Bioma Caatinga, apesar de ser o único no mundo, enfrenta grande processo de destruição. Por este motivo, faz-se necessário:

1. Refletir sobre a relação homem $x$ meio;

2. Identificar quais os principais problemas ambientais apontados na música, relacionado às causas, bem como discutindo possíveis soluções;

3. Pesquisar os problemas ambientais que afetam sua cidade (escola, rua, bairro, etc.), registrando as causas e possíveis consequências destes para a população local. Tal pesquisa pode ser realizada em grupos através de registro fotográfico. Ao final pode ser realizada uma exposição com os principais problemas identificados pelos alunos, culminando com uma grande discussão, onde poderá ser feito um levantamento de possíveis alternativas para minimizar tais problemas.

4. Apontar os elementos que compõem o Bioma Caatinga;

5. Destacar qual a importância do Bioma Caatinga para a sobrevivência da população nordestina;

6. Despertar nos alunos, através da educação ambiental, a importância da manutenção do meio ambiente, bem como a necessidade de convivência harmoniosa com o semiárido de modo a preservar os seus elementos naturais e culturais, com vista a um desenvolvimento econômico pautado na sustentabilidade local, podendo esta culminância ser desenvolvida através de uma produção textual.

Faz-se oportuno ressaltar a necessidade de adequação dos objetivos delineados para as discussões em torno das músicas selecionadas, levando em consideração a idade/série, bem como as características do espaço escolar, aqui considerando o ambiente ao entorno da escola, como também o espaço vivido dos alunos, como forma de buscar uma maior profundidade e significância dos conteúdos trabalhados.

\section{Tecendo algumas considerações}

0 presente artigo se configura em uma proposta didático-pedagógica para se trabalhar conteúdos geográficos levando em consideração os elementos que constituem a paisagem local, utilizando para tanto a música como recurso metodológico, haja vista todas as vantagens apontadas ao longo do texto. Neste caso, recorreram-se as músicas de Luiz Gonzaga para se trabalhar conteúdos referentes à Geografia do Nordeste, utilizando os elementos regionais presentes nas referidas canções.

No caso presente, a utilização de letras musicais que retratem a realidade vivida dos alunos pode vir a propiciar, além de uma melhor compreensão dos conteúdos, uma consequente valorização dos elementos materiais e imateriais que compõe a região semiárida, podendo esta culminar em uma maior conservação dos recursos naturais disponíveis na citada área.

Assim sendo, pode dizer que a música é um importante instrumento no processo de ensinoaprendizagem, principalmente pela variedade de assuntos abordados, cabendo ao professor à escolha da letra e a devida adequação ao conteúdo. 


\section{Referências}

BRASIL, Ministério Da Integração Nacional Cartilha Nova Delimitação do Semi-árido, Brasília, 2005. $<$ http://www.integracao.gov.br>. Acesso em: 18 de fevereiro de 2008.

BRASIL, Parâmetros Curriculares Nacionais: História e Geografia. Ministério da educação. Secretaria de Educação Fundamental. 3 ed. Brasília, 2001. 166p.

BRAGA, O. R. Educação e convivência com o semi-árido: introdução aos fundamentos do trabalho político-educativo no semi-árido Brasileiro. In: KÜSTER, A; MATTOS, B. H. O. M. Educação no contexto do semi-árido brasileiro. Fortaleza: Fundação Konrad Adenauer, 2004.

CAVALCANTI, L. S. Geografia e práticas de ensino. Goiânia: Alternativa, 2002.

CAVALCANTI, E. Para compreender a desertificação. Recife: FUNDAJ, 2003.

DOHME, V. Atividades lúdicas na educação: o caminho de tijolos amarelos do aprendizado. 5 ed. Petrópolis, RJ: Vozes, 2009.

FERREIRA, M. Como usar a música na sala de aula. São Paulo: Contexto, 2010.

FRANÇA, F.N.C. \& FIGUEIREDO, A.Z.Q. Educação ambiental para o semiárido do Ceará. Fortaleza: Secretaria dos Recursos Hídricos, 2010.

FREIRE, P. Pedagogia da Autonomia: saberes necessários à prática educativa. 39 ed. São Paulo: Paz e Terra, 2009.

KAERCHER, N. A. O gato comeu a geografia crítica? alguns obstáculos a superar no ensinoaprendizagem de Geografia. In: PONTUSCHKA, N.N, OLIVEIRA, O. (orgs). Geografia em Perspectiva. São Paulo: Contexto, 2002. p. 221 - 231.

MELO, E. C. L. de et. al. Geografia. Disponível em : < http://www.vitoria.es.gov.br/ arquivos/20100218_ens_fund_dir_geografia.pdf> Acesso em: 20 de março de 2009.

MELO, J. B. A. de; PEREIRA, R. A. \& PEREIRA, S. S. O semi-árido brasileiro: políticas públicas versus ampliação das vulnerabilidades locais. In: Anais ... Fórum Internacional do Meio Ambiente - A conferência da Terra. Questões globais e solução locais. João Pessoa: Editora Universitária da UFPB, 2008. p. $1571-1578$.

OLIVEIRA, H. C. M. de et. al. A música como um recurso alternativo nas práticas educativas em Geografia: algumas reflexões. In: Revista Caminhos de Geografia. Uberlândia/MG, ano 8, n. 15, jun/2005, p. 73-81.

PINHEIRO, E. A. et. al. O nordeste brasileiro nas músicas de Luiz Gonzaga. Caderno de Geografia, Belo Horizonte, v.14, n. 23, $2^{\circ}$ sem/2004, p. 103-111.

PINTO, O. A. S. Dom Sertão, Dona Seca. João Pessoa: A União, 2002.

VESENTINI, J. W. Educação e ensino da Geografia: instrumentos de dominação e/ou libertação. In: CARLOS, A. F. A. (org). A Geografia em Sala de Aula. São Paulo: Contexto, 2001. 144p. p. 14-31.

Geografia Ensino \& Pesquisa, v. 16, n.3 p. $137-148$, set./dez. 2012 


\section{Correspondência:}

Suellen Silva Pereira - Rua Maria do Carmo Nóbrega, 60, Três Irmãs, Campina Grande, Paraíba, Brasil. CEP: 58423-127.

E-mail: suellenssp@hotmail.com

Recebido em 15 de dezembro de 2011.

Revisado pelo autor em 04 de setembro de 2012.

Aceito para publicação em 20 de novembro de 2012. 